\title{
STUDY ON DISRUPTIONS IN THE QUALITY MANAGEMENT SYSTEM IN COMPLIANCE WITH ISO 9001:2015
}

\author{
Mariusz J. LIGARSKI \\ Silesian University of Technology, Faculty of Organization and Management, Poland; mariusz.ligarski@polsl.pl, \\ ORCID: 0000-0002-5754-2324
}

Purpose: The objective of the study is to present the results of a study on disruptions occurring in organizations, certified for compliance with the requirements of ISO 9001:2015, as well as the results of analysis on the results obtained.

Design/methodology/approach: The study was carried out on a group of 69 organizations certified by a large international certification body. The original method of analyzing disruptions in systems, based on non-compliance identified during third-party audits, was used in the study.

Findings: The results of the study have been presented. A summary of the number of noncompliances identified in relation to the sections and subsections of the ISO 9001:2015 standard has been prepared. A summary of the number of non-compliances identified in small, mediumsized and large organizations in relation to subsections of the standard has also been drawn up. Practical implications: It has been pointed out that the evaluation of disruptions in the system should consist in analysis of their causes and taking actions that will protect the organization from further occurrences. Such knowledge should help organizations better maintain and improve quality management systems.

Originality/value: Specific sections and subsections of the standard, in which problems have been identified, were indicated. An attempt was made to determine the impact of the size and type of the organization's activities on the type of disruptions. Yet again, it was confirmed that examination of problems with the original method, based on the results of third-party audits, provides objective information on non-compliance in organizations.

Keywords: study on disruptions, original method, nonconformity, ISO 9001:2015, quality management system.

Category of the paper: Research paper. 


\section{Introduction}

Quality management systems operating in compliance with ISO 9000 standards are the most widespread standardized management systems in the world. For many years, various studies have been conducted on these systems. The normative basis of these systems is changing to better adapt to the current management trends and give an organization the opportunity to use comprehensive system solutions, in order to organize and streamline its operations. The last amendment to the ISO 9001 standard in 2015, in addition to adaptation of requirements to the current management trends, implemented new requirements that should help the organization to better adapt to the environment and changes taking place within it in turbulent times. Despite many years of experience in functioning of systems in various industries, adapting the standard of requirements to the current needs, many organizations are struggling with various problems regarding the functioning of the quality management system (Chen et al., 2016; Francis, 2011; Sampaio et al., 2009; Claver, and Tari, 2003). The author of the study conducts comprehensive studies on functioning and improvement of systems for many years (Ligarski, 2010, 2014). One of the mainstreams of this study are disruptions occurring in systems. The author has developed an innovative method for examining problems occurring in systems (Ligarski, 2012). This method involves analysis of the disruptions based on the results of the third-party audits. Disruptions are therefore examined on the basis of information obtained from outside of the organization, and not as it is usually implemented, on the basis of internal data of the organization. The results so far indicate great possibilities of this method (Ligarski, 2013, 2018; Ligarski, and Juszczak-Wiśniewska, 2016). However, there is a problem with access to data certification bodies are unwilling to share the results of conducted audits. In this study, we managed to examine disruptions occurring in quality management systems certified for compliance with requirements of the ISO 9001:2015 standard. These are first such studies carried out in organizations, in which systems based on the requirements of the ISO 9001 standard from 2015 are operating.

The objective of the study is to present the results of a study on disruptions occurring in organizations, certified for compliance with the requirements of ISO 9001:2015, as well as the results of analysis on the results obtained.

\section{Material and methodology}

The study was carried out on a group of 69 organizations certified by one of the largest certification bodies operating in Poland. Organizations are of various sizes and profiles of activities, which is shown as attributing to relevant industries. The size of organization was 
determined based on the employment level, and organizations were divided into categories of small, medium-sized and large organizations (Table 1). All examined organizations utilize a certified quality management system in accordance with the requirements of ISO 9001:2015. In the study, the original method of examining disruptions in the quality management system was used, which was characterized in detail in (Ligarski, 2012).

\section{Table 1.}

Organizations involved in the study by employment

\begin{tabular}{|c|c|c|}
\hline Size of the organization & Number & Percentage share \\
\hline Small organizations (up to 50 employees) & 27 & 39.13 \\
\hline Medium-sized organizations (from 51 to 250 employees) & 31 & 44.93 \\
\hline Large organizations (over 251 employees) & 11 & 15.94 \\
\hline Total & 69 & 100 \\
\hline
\end{tabular}

Source: own work.

The third party audit reports prepared by auditors of the certification body were subject to examination. Non-compliances, for which non-compliance cards were drafted, were taken into account. Non-compliance, in accordance with the definition, is understood as non-fulfillment of requirements set out in the ISO 9001 standard, and it is attributed to the respective subsection of this standard. The examination was carried out by a large certification body in the period from April 2018 to June 2018.

\section{Study results and discussion}

The results of the study were presented in three tables. Table 2 shows nonconformities with the main sections of the ISO 9001:2015 standard.

\section{Table 2.}

Summary of the number of nonconformities identified in relation to main sections of the ISO 9001:2015 standard

\begin{tabular}{|l|c|c|}
\hline Main sections of the ISO 9001:2015 standard & $\begin{array}{c}\text { Number of } \\
\text { nonconformities }\end{array}$ & Percentage share \\
\hline 4. Context of the organization & 8 & 6.20 \\
\hline 5. Leadership & 6 & 4.65 \\
\hline 6. Planning & 7 & 5.43 \\
\hline 7. Support & 71 & 55.04 \\
\hline 8. Operation & 22 & 17.05 \\
\hline 9. Performance evaluation & 12 & 9.30 \\
\hline 10. Improvement & 3 & 2.33 \\
\hline Total & 129 & 100 \\
\hline
\end{tabular}

Source: own work. 
When analyzing the obtained results, it should be stated that the most nonconformities more than half of all - were attributed to section 7 of the standard (Support). This section concerns resources, competences, awareness, communication and documented information. Therefore, it can be concluded that many of the problems identified in the systems relate to the soft factor. The second most frequently indicated section is section 8, Operational activities, based on which almost $17 \%$ of non-compliances were found. This section deals with planning, requirements, design and development, production and service delivery, release of products and services, and supervision over non-compliant outputs. It can therefore be assumed that the second problem to identify is hard factors. However, the division into hard and soft factors is not quite proper, as disruptions related to hard factors may result from problems related to soft factors. The third most frequent problem indicated is section 9, Evaluation of results of actions, in which over $9 \%$ of non-compliances were found. This section describes monitoring, measurement, analysis, evaluation, internal audit and management review, i.e. the mechanisms in the system responsible for monitoring, measurement and evaluation. Attribution of non-compliance to the main sections of the standard shows the main trends regarding identified problems. To precisely trace the occurrence of specific disruptions, it is necessary to attribute non-compliance to specific subsections of the ISO 9001:2015 standard.

Table 3 shows nonconformities attributed to the main detailed sections of the ISO 9001:2015 standard.

Table 3.

Summary of number of nonconformities identified in relation to subsections of the ISO 9001:2015 standard

\begin{tabular}{|l|c|c|}
\hline Subsections of the ISO 9001:2015 standard & $\begin{array}{c}\text { Number of } \\
\text { nonconformities }\end{array}$ & Percentage share \\
\hline 4.1 Understanding the organization and its context & 1 & 0.78 \\
\hline 4.2 Understanding the needs and expectations of interesting parties & 4 & 3.10 \\
\hline 4.3 Determining the scope of the quality management system & 2 & 1.55 \\
\hline 4.4 Quality management system and its processes & 1 & 0.78 \\
\hline 5.1 Leadership and commitment & 0 & 0 \\
\hline 5.2 Policy & 6 & 4.65 \\
\hline 5.3 Organizational roles, responsibilities and authorities & 0 & 0 \\
\hline 6.1 Actions to address risks and opportunities & 4 & 3.10 \\
\hline 6.2 Quality objectives and planning to achieve them & 3 & 2.32 \\
\hline 6.3 Planning of changes & 0 & 0 \\
\hline 7.1 Resources & 32 & 24.81 \\
\hline (7.1.1 General) & $(0)$ & $(0)$ \\
\hline (7.1.2 People) & $(4)$ & $(3.10)$ \\
\hline (7.1.3 Infrastructure) & $(11)$ & $(8.53)$ \\
\hline (7.1.4 Environment for the operation of processes) & $(7)$ & $(5.43)$ \\
\hline (7.1.5 Monitoring and measuring resources) & $(6)$ & $(4.65)$ \\
\hline (7.1.6 Organizational knowledge) & $(4)$ & $(3.10)$ \\
\hline 7.2 Competence & 9 & 6.98 \\
\hline 7.3 Awareness & 8 & 6.20 \\
\hline 7.4 Communication & 7 & 5.43 \\
\hline 7.5 Documented information & 15 & 11.63 \\
\hline
\end{tabular}


Cont. table 3.

\begin{tabular}{|l|c|c|}
\hline 8.1 Operational planning and control & 0 & 0 \\
\hline 8.2 Requirements for products and services & 3 & 2.32 \\
\hline 8.3 Design and development of products and services & 4 & 3.10 \\
\hline 8.4 Control of externally provided processes, products and services & 3 & 2.32 \\
\hline 8.5 Production and service provision & 10 & 7.75 \\
\hline 8.6 Release of products and services & 1 & 0.78 \\
\hline 8.7 Control of nonconforming outputs & 1 & 0.78 \\
\hline 9.1 Monitoring, measurement, analysis and evaluation & 1 & 0.78 \\
\hline 9.2 Internal audit & 3 & 2.32 \\
\hline 9.3 Management review & 8 & 6.20 \\
\hline 10.1 General [Improvement] & 0 & 0 \\
\hline 10.2 Nonconformity and corrective action & 3 & 2.32 \\
\hline 10.3 Continual improvement & 0 & 0 \\
\hline TOTAL & 129 & 100 \\
\hline
\end{tabular}

Source: own work.

When analyzing the results obtained in Table 3, it should be stated that most nonconformities - almost $25 \%$ of them - were found in subsection 7.1, Resources. In order to better define the type of problems, another subsections included in this section (in parentheses) are listed, including the number of non-compliances and their percentage. The greatest number of non-compliances was found in subsection 7.1.3, Infrastructure, which confirms that auditors pay attention to premises, equipment and other infrastructure, necessary for proper functioning of processes. The second most frequently indicated problem is 7.1.4, Environment of functioning of processes, where, apart from physical factors (temperature, lighting, noise), attention is paid to social and psychological factors (reducing stress levels, serenity and emotional protection). The second most frequently indicated problem is the Documented information, described in subsection 7.5. Auditors pay special attention to the issues of supervision over documented information. Despite many years of experience and liberalization of documentation requirements, organizations continue to face problems with documented information. The third area, where the most non-compliances were identified, is subsection 8.5, Production and provision of services. The most problems were found in the supervised conditions, in which the production and delivery of service should be carried out. Part of the organization has difficulties related to identification and traceability of the output data. The next subsections, in which a large number of non-compliances was identified, are sections 7.2, Competences, 7.3, Awareness, 9.3, Management review, and 7.4, Communication. Three of the sections highlight soft factors in management of the organization. Organizations have problems with taking actions aimed at acquiring necessary competencies by employees, including trainings. The problem is also to raise employees' awareness of their role in the quality management system, as well as the knowledge and implementation of the organization's goals. Communication in a large part of the organization leaves a lot of room for improvement. The identified non-compliances regarding soft factors confirm well-known regularity, that organizations make substantial errors and commit negligence at the stage of creating the system, which relate to raising awareness, competence improvement, building a system consisting of many components, which should be well-connected. These errors and negligence 
significantly affect functioning of the system, even many years after its first certification. Later on, it is extremely difficult to change the unfavorable attitude of some employees to the system, and the problems in this area are usually repeated and, over time, they are intensifying. There are also frequent problems with the management review. Organizations find it difficult to properly analyze data prepared for review and to use the information obtained in the decision making process. This shows insufficient preparation and involvement of top management in handling the system and inability to use the obtained information for improvement.

In the next summary list (Table 4), nonconformities were attributed to the organization by size. The summary shows the number of non-compliances in individual subsections of the standard in small, medium-sized and large organizations. This type of summary can be employed to analyze whether the size of organization affects the emerging problems, and whether it is possible to determine the organization's susceptibility to occurrence of specific disruptions, depending on its size.

\section{Table 4.}

Summary of number of nonconformities identified in small, medium-sized and large organizations, in relation to subsections of the ISO 9001:2015 standard

\begin{tabular}{|c|c|c|c|}
\hline \multirow[t]{2}{*}{ Subsections of the ISO 9001:2015 standard } & \multicolumn{3}{|c|}{$\begin{array}{l}\text { Number of nonconformities } \\
\text { identified in organization }\end{array}$} \\
\hline & small & $\begin{array}{l}\text { medium- } \\
\text { sized }\end{array}$ & large \\
\hline 4.1 Understanding the organization and its context & 1 & 0 & 0 \\
\hline 4.2 Understanding the needs and expectations of interesting parties & 2 & 2 & 0 \\
\hline 4.3 Determining the scope of the quality management system & 0 & 2 & 0 \\
\hline 4.4 Quality management system and its processes & 1 & 0 & 0 \\
\hline 5.1 Leadership and commitment & 0 & 0 & 0 \\
\hline 5.2 Policy & 0 & 3 & 3 \\
\hline 5.3 Organizational roles, responsibilities and authorities & 0 & 0 & 0 \\
\hline 6.1 Actions to address risks and opportunities & 2 & 2 & 0 \\
\hline 6.2 Quality objectives and planning to achieve them & 2 & 1 & 0 \\
\hline 6.3 Planning of changes & 0 & 0 & 0 \\
\hline 7.1 Resources & 14 & 14 & 4 \\
\hline (7.1.1 General) & $(0)$ & $(0)$ & $(0)$ \\
\hline (7.1.2 People) & (2) & (2) & $(0)$ \\
\hline (7.1.3 Infrastructure) & (4) & (4) & (3) \\
\hline (7.1.4 Environment for the operation of processes) & (3) & (3) & (1) \\
\hline (7.1.5 Monitoring and measuring resources) & (3) & (3) & $(0)$ \\
\hline (7.1.6 Organizational knowledge) & (2) & (2) & $(0)$ \\
\hline 7.2 Competence & 5 & 4 & 0 \\
\hline 7.3 Awareness & 3 & 5 & 0 \\
\hline 7.4 Communication & 3 & 4 & 0 \\
\hline 7.5 Documented information & 4 & 8 & 3 \\
\hline 8.1 Operational planning and control & 0 & 0 & 0 \\
\hline 8.2 Requirements for products and services & 1 & 2 & 0 \\
\hline 8.3 Design and development of products and services & 0 & 4 & 0 \\
\hline 8.4 Control of externally provided processes, products and services & 2 & 0 & 1 \\
\hline 8.5 Production and service provision & 2 & 7 & 1 \\
\hline 8.6 Release of products and services & 0 & 1 & 0 \\
\hline 8.7 Control of nonconforming outputs & 0 & 1 & 0 \\
\hline
\end{tabular}


Cont. table 4.

\begin{tabular}{|l|c|c|c|}
\hline 9.1 Monitoring, measurement, analysis and evaluation & 0 & 1 & 0 \\
\hline 9.2 Internal audit & 0 & 2 & 1 \\
\hline 9.3 Management review & 5 & 2 & 1 \\
\hline 10.1 General [Improvement] & 0 & 0 & 0 \\
\hline 10.2 Nonconformity and corrective action & 0 & 3 & 0 \\
\hline 10.3 Continual improvement & 0 & 0 & 0 \\
\hline TOTAL & 47 & 68 & 14 \\
\hline
\end{tabular}

Source: own work.

Using statistical methods, an attempt can be made to check whether the differences are statistically significant. By using the chi-square test of independence to list the number of non-compliances in individual subsections of the standard, depending on size of the organization, an attempt can be made to determine the relationship between the size of organization and the types of identified non-compliances in individual sections of the standard. The average number of non-compliances per organization was also calculated: small organization -1.74 ; medium-sized organization -2.19 ; large organization -1.27 . By using the two-sample location test, it can be verified whether the differences between samples are statistically significant. This type of statistical analysis was performed in previous studies on the ISO 9001:2008 standard. In the light of relatively small amount of data, only after collecting more data, such analyses will be carried out. At present, it is possible to compare which non-compliances are identified in small, medium-sized and large organizations. In several subsections, it can be noted that problems are identified in small and medium-sized organizations, and that they do not occur in large organizations. It most probably depends on many factors, including methods of building and implementing a quality management system.

With the data obtained, an attempt can also be made to try to attribute non-compliances to organization groups, broken down into production and service lines, and to the industries defined by the organization. Considering size of the study and the fact that the problems with requirements of ISO 9001:2015 have only just begun, such summaries will not be presented.

\section{Conclusions}

The conducted studies on disruptions in the quality management system, for the first time conducted on a sample of organizations certified for compliance with the requirements of the ISO 9001:2015 standard, provided a lot of interesting information. Yet again, it was confirmed that examination of problems occurring in systems with the original method, based on the results of third-party audits, provides objective information on nonconformities. Non-compliances are found and documented by auditors of the certification body, who have adequate competence and experience in examining compliance of the system with requirements. Non-compliance cards issued by them oblige organizations to take corrective 
actions, which are also documented. These types of activities naturally force examining the problem precisely in order to identify it, as well as they force acting in order to eliminate the problem, along with analyzing its causes. Examination of disruptions in the quality management system indicates areas, in which such disruptions occur the most often. The results presented in the study show that more than half of the identified disruptions are attributed to section 7, Support, of the ISO 9001:2015 standard. A detailed analysis of the obtained information allows to indicate the appropriate subsections of the standard, in which the disruptions were identified. In the conducted study, problems in the area of resources, documented information and competences are mostly identified. The work also aimed at considering whether the size of organization affects the type of problems and number of problems. It is also possible to consider whether individual disruptions are related to the profile of organization's activity and the specific industry, to which it was attributed. Thus, the conducted study enables a precise identification of problems found in certified quality management systems. Attributing problems to specific sections and subsections of the ISO 9001:2015 standard, considering whether the size and profile of the organization's activities have an impact on emerging disruptions. Evaluation of disruptions in the quality management system should consist in analysis of their causes and taking actions that will protect the organization from further occurrences. Based on knowledge about disruptions, causes and problem formation mechanism may be analyzed. The obtained knowledge should be used to prevent the formation of disruptions. The organization, knowing the potential causes of emerging problems and their formation mechanism, may take actions that will prevent the occurrence of problems, that will enable them to be quickly identified and solved in the initial phase of formation. Therefore, there should be no serious disruptions that could have a significant negative impact on organizations.

Obtained results regarding disruptions identified in a certified quality management system, compliant with the requirements of the ISO 9001:2015 standard, provide valuable reference material to previously conducted studies based on the ISO 9001:2008 standard. The comparison of results of the study on disruptions, identified in two consecutive editions of the ISO 9001 standard, should provide a lot of interesting information. First, identifying the disruptions and attributing them to the respective subsections of the standard. It should clearly determine to which areas the non-compliances are attributed, whether the areas repeat or whether there are new areas where disruptions were found. Such information should allow to answer the question of whether the organizations have dealt with previously identified problems, which of them have been actually eliminated and which are unfortunately recurrent. Are there any new problems related to new or developed requirements contained in the ISO 9001:2015 standard? Such knowledge is very useful in maintaining and improving systems. The first step should be to eliminate or at least significantly reduce disruptions, which should affect the efficiency of the system and the possibility of its development. Not solving problems on a regular basis will result, over time, in their growth and the increasingly negative impact on organizations. 
This is why quick diagnosis of disruptions and the ability to remove them, along with investigating actual causes of such phenomena, play such an important role. Only activities aimed at eliminating the real causes of problems should secure the organization from their recurrence.

\section{Acknowledgements}

This paper was financed from the resources of the Silesian University of Technology, project no. BK-235/ROZ-1/2020 (13/010/BK_20/0042).

\section{References}

1. Chen, C.K., Anchecta, K., Lee, Y.D., Dahlgaard, J.J. (2016). A stepwise ISO-based TQM implementation approach using ISO 9001:2015. Management and Production Engineering Review, 7(4), pp, 65-75.

2. Claver, E., Tari, J.J. (2003). Levels of quality management in certified firms. TQM \& Business Excellence, 14(9), pp. 981-998.

3. Francis, J.R. (2011). A Framework for understanding and researching audit quality. Auditing: A Journal of Practice \& Theory, 30(2), pp. 125-152.

4. Ligarski, M.J. (2010). Podejście systemowe do zarządzania jakościa $w$ organizacji. Gliwice: Wyd. Politechniki Śląskiej.

5. Ligarski, M.J. (2012). Problem identification method in certified quality management systems. Quality \& Quantity, 46, pp. 315-321.

6. Ligarski, M.J. (2013). Problems examination in quality management system. Acta technologica agriculturae, 4, pp. 106-110.

7. Ligarski, M.J. (2014). Diagnoza systemu zarządzania w polskich organizacjach. Problemy Jakości, 5, pp. 14-22.

8. Ligarski, M.J. (2018). Zastosowanie metody badań zaburzeń w przedsiębiorstwach na przykładzie przemysłu chemicznego. Przem. Chem. 97(4), pp, 643-644.

9. Ligarski, M.J., Juszczak-Wiśniewska, A. (2016). Innowacyjna metoda do badania zaburzeń w systemie zarządzania jakością - pierwsze zestawienie wyników. In: R. Knosala (Ed.), Innowacje w zarzadzaniu i inżynierii produkcji (pp. 237-245). Opole: Oficyna Wydawnicza Polskiego Towarzystwa Zarządzania Produkcją.

10. Sampaio, P., Saraiva, P., Rodrigues, A.G. (2009). ISO 9001 certification research: questions, answers and approaches. International Journal of Quality and Reliability Management, 1, pp. 38-58. 